\title{
Proliferation activity in the polyps of Cassiopea xamachana: where the planuloid buds grow
}

\author{
Valeriia Khabibulina ${ }^{1}$ and Viktor Starunov ${ }^{2}$ \\ ${ }^{1}$ Department of Invertebrate Zoology, Faculty of Biology, Saint Petersburg State University, \\ Universitetskaya nab., 7-9, Saint Petersburg, 199034, Russian Federation \\ ${ }^{2}$ Zoological Institute, Russian Academy of Sciences, Universitetskaya nab., 1, \\ 199034, Saint Petersburg, Russian Federation \\ Address correspondence and requests for materials to Valeriia Khabibulina, \\ khabvaleriya@yandex.ru
}

\begin{abstract}
Polyps of the Cassiopeidae family possess a unique type of asexual reproduction by producing free-swimming buds - planuloids. The process of planuloid development and transformation to polyp has been described earlier, however, the source of tissue formation is still poorly studied. Using the method of EdU incorporation we have analyzed DNA synthesis activity during planuloid formation and growth in Cassiopea xamachana. We revealed the active proliferation zone at the early stage of bud formation. This zone continued to function during planuloid growth, providing the formation of polyp structures, and preserved in polyp calyx after metamorphosis. Its proliferation activity varied at different growth stages, whereas the localization remained relatively the same.
\end{abstract}

Keywords: cnidaria, budding, development, polyp, scyphozoa, proliferation, asexual reproduction

\section{Introduction}

Citation: Khabibulina, V. and Starunov, V. 2021. Proliferation activity in the polyps of Cassiopea xamachana: where the planuloid buds grow. Bio. Comm. 66(4): 333-340. https://doi.org/10.21638/spbu03.2021.406

Authors' information: Valeriia Khabibulina, Research Assistant, orcid.org/0000-0002 5019-8604; Viktor Starunov, PhD, Senior

Researcher, orcid.org/0000-0002-9001-2069

Manuscript Editor: Pavel Skutschas,

Department of Vertebrate Zoology, Faculty of Biology, Saint Petersburg State University,

Saint Petersburg, Russia

Received: May 2, 2021;

Revised: September 6, 2021;

Accepted: September 21, 2021.

Copyright: (c) 2021 Khabibulina and Starunov. This is an open-access article distributed under the terms of the License Agreement with Saint Petersburg State University, which permits to the authors unrestricted distribution, and self-archiving free of charge.

Funding: The work was supported by the Zoological Institute of the Russian Academy of Sciences (NIOKTR: AAAA-A19-119020690076-7).

Ethics statement: This paper does not contain any studies involving human participants or animals performed by any of the authors.

Asexual reproduction is widespread in Cnidaria (Fautin, 2002). Polyps can reproduce by various ways, including fragmentation, longitudinal or transversal division and budding (Boero et al., 2002; Bocharova and Kozevich, 2011; Schiariti et al., 2014). The process of lateral budding is the most studied, primarily in Hydra sp. (Galliot, 2012). However, little is known about other types of budding, found in different cnidarian groups. Particularly in Scyphozoa, reproduction by budding plays a significant role in jellyfish bloom formation, therefore investigation of the ecological features of this process is the object of intense attention (Arai, 2008; Lucas et al., 2012). However, morphological aspects of bud formation and development are often left out.

The budding type descriptions in Scyphozoa were mostly done in life cycle studies. It was shown that scyphozoan polyps have several ways to propagate. Many scyphozoan species reproduce by lateral budding, for example, semaestomeans Aurelia aurita (Spangenberg, 1965), Phacellophora camtschatica (Widmer, 2006) and rhizostomean Catostylus mosaicus (Pitt, 2000). During lateral budding, a new polyp almost completely forms at the calyx of the parent individual and preserves this anatomical connection for long time. Stolonial budding is much less common and is described only in a few species, such as Aurelia aurita (Gilchrist, 1937), Sanderia malayensis (Adler and Jarms, 2009), Rhizostoma pulmo (Fuentes et al., 2011). In this case buds develop at body processes - stolons which are usually used for polyp fixation or moving. Numerous scyphozoan polyps produce resting buds - podocysts (Arai, 2008). Podocysts are formed from the polyp stalk tissues, covered by thick cuticle (Chapman, 1968; Ikeda et al., 2011). Finally, longitudinal division has also been observed in some species 


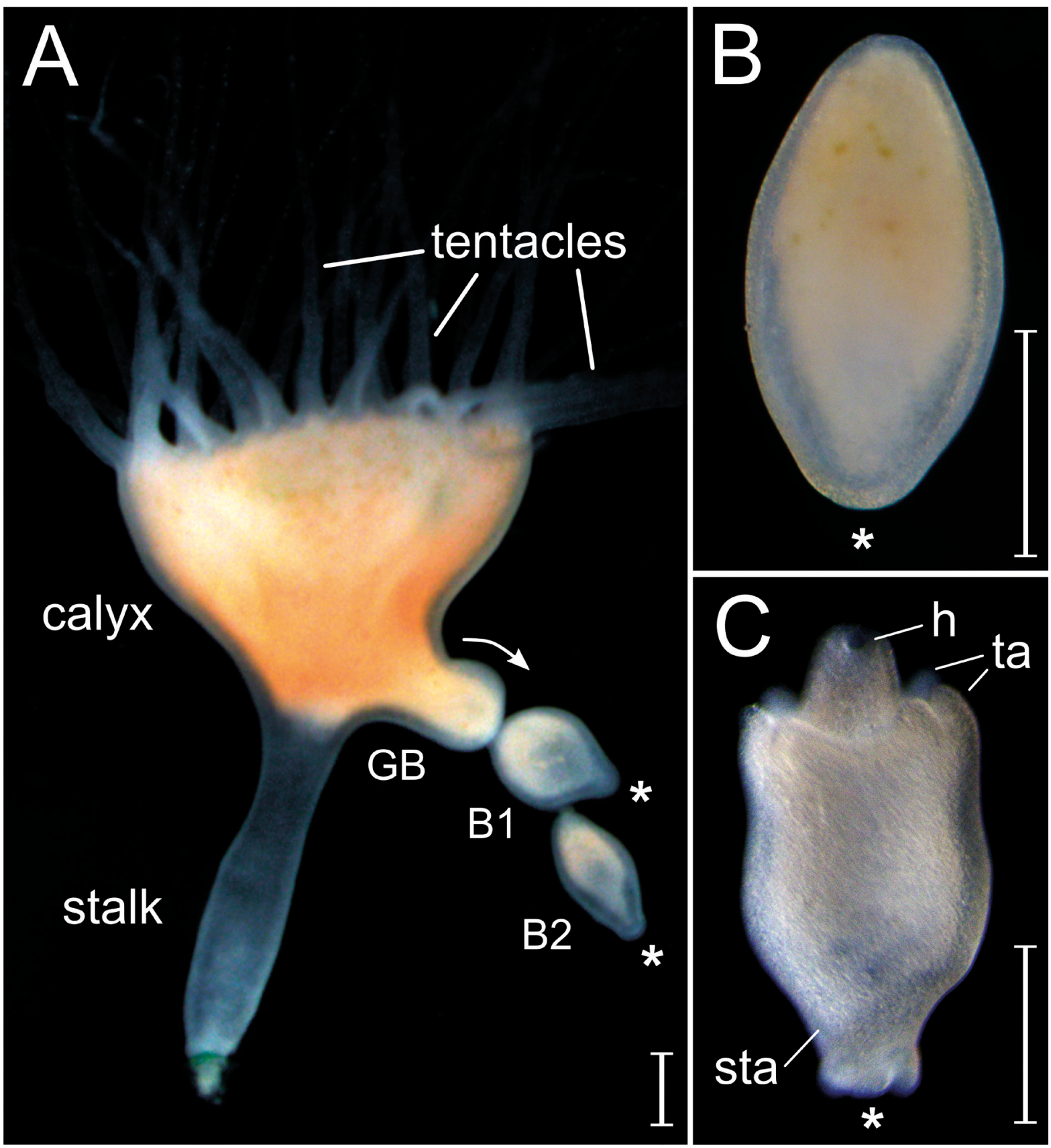

Fig. 1. Gross morphology of the polyp and planuloids of C. xamachana.

A - polyp during the budding process with one growing bud and two planuloid buds in chain, B - planuloid just after separation, C - late planuloid with organ anlages. Abbreviations: B1, B2 - planuloid buds, GB - growing bud, h - hypostome anlage, sta - stalk anlage, ta - tentacle anlage. The functionally anterior end of the planuloid is marked with an asterisk; the arrow shows the direction of bud growth. Scale bar $-500 \mu \mathrm{m}$.

(Pitt, 2000; Widmer, 2006, 2008). In all these cases newly formed polyps stay close to the parent individual, which limits the population spread.

Among these budding types, planuloid budding stands out because the forming buds are motile. It was observed in several species of the rhizostomean suborder Kolpophorae: Cephea cephea (Sugiura, 1966), Cotylorhiza tuberculata (Kikinger, 1992), Mastigas papua (Sugiura, 1963); and order Coronatae: Nausithoe aurea (da Silveira and Morandini, 1997) and Nausithoe plan- ulophora (Werner, 1971). The budding process is well studied in polyps of the Cassiopeidae family (Rhizostomeae: Kolpophorae) using the methods of histology (Bigelow, 1900), scanning (Van Lieshout and Martin, 1992) and transmission electron microscopy (Hofmann and Gottlieb, 1991). The first stage of bud growth is similar to that of lateral budding. A rounded evagination forms at the base of the polyp calyx in one or several sites simultaneously. The evagination quickly grows and forms a ciliated lemon-shaped bud called a planuloid (Fig. 1A). 
The planuloid detaches and swims away, wherein the distal end of the growing bud becomes the functionally anterior end of the planuloid (Fig. 1B). Often a new bud starts to grow before the separation of the previous planuloid. In this way a chain of up to 5-6 planuloids can form at one budding site (Hofmann et al., 1978; our observations). During the swimming period the planuloid forms tentacles and hypostome anlages at the posterior end (Fig. 1C). Soon it attaches with the anterior end and transforms to a young polyp (Thieme and Hofmann, 2003).

It was repeatedly shown that both tissue layers are involved in the early stages of bud development (Bigelow, 1900; Hofmann et al., 1978; Van Lieshout and Martin, 1992). Besides the migration of epidermal cells into the bud, evagination was traced using vital markers (Hofmann and Gottlieb, 1991). However, no cell division was observed in the growing bud or planuloid, and it is still unclear where the proliferation zones are located. To find out the cell source of planuloid formation and growth we have studied the dynamics of DNA synthesis during the budding process in Cassiopea xamachana Bigelow, 1892.

\section{Material and methods}

A culture of C.xamachana polyps was maintained in artificial sea water with $35 \%$ salinity at room temperature in plastic culture tanks. Polyps were regularly fed on the nauplii of Artemia. In laboratory conditions, planuloids formed constantly without any induction.

Polyps with growing buds and planuloids at different developmental stages were collected in small plastic dishes and incubated for 1-1.5 hours at room temperature in a $50-\mu \mathrm{M}$ solution of 5-ethynyl-2'-deoxyuridine $(\mathrm{EdU})$ in filtered artificial sea water. Longer incubation time led to excess labeling. After incubation the specimens were washed 3 times for 10 minutes in filtered sea water, then anesthetized in $7.5 \% \mathrm{MgCl}_{2}{ }^{*} 6 \mathrm{H}_{2} \mathrm{O}$ until complete musculature relaxation, and fixed in $4 \%$ paraformaldehyde on $1 \mathrm{X}$ Phosphate-buffered saline (PBS) at room temperature for 1-2 hours. After fixation, specimens were washed in PBS with $1 \%$ Tween-20 (PBT) 3 times for 15 minutes.

All specimens were labeled with fluorescent Cy3 dye following the standard protocol (Shunatova and Borisenko, 2020). After staining, specimens were washed in PBS 3 times for 15 minutes, additionally labeled with DAPI, and mounted in Mowiol 4-88 (Wurm et al., 2010). The confocal stacks were acquired with a Leica TCS SP5 Laser Scanning Confocal Microscope, and analyzed using Fiji (Schindelin et al., 2012).

Calculation of the labeled nuclei was done for 4 specimens at every stage of the planuloid development. A set of sagittal confocal slices of the whole speci- men $10-15 \mu \mathrm{m}$ thick were used for each calculation. Thus, only two tissue layers were included in counting and not the whole animal. In the case of polyps, every sample was divided in areas of $100 \times 100 \mu \mathrm{m}^{2}$, in which labeled nuclei were counted; in the case of planuloids, the labeled nuclei were counted in the whole specimens and then recalculated for $100 \times 100 \mu \mathrm{m}^{2}$ areas. The value of labeled nuclei in these areas was averaged. In every case the range of extreme values is shown, taking into account the standard deviation, calculated in Microsoft Office Excel.

\section{Results}

We determined several zones of active DNA synthesis at different stages of budding growth and planuloid development in C.xamachana. In a polyp with growing buds, two zones of EdU incorporation were observed (Fig. 2A). The first one was situated at the large region of polyp calyx from its base to the oral disk. The labeled nuclei were distributed evenly. Solitary labeled nuclei were found in tentacles and stalk nearby the calyx. The second zone was located throughout the bud evagination from the base to the distal end, except the small area at the tip (Fig. 2B). The EdU signals in the evagination were located very densely, so that individual nuclei were sometimes indistinguishable. The number of labeled nuclei in the evagination area was about $120-140$ per $100 \times 100 \mu \mathrm{m}^{2}$. The EdU incorporation in the bud evagination was notably higher than in the calyx. However, we never observed any changes in labeling rate near the bud evagination. At this area as well as in the calyx, the number of labeled nuclei varied from 45 to 65 per $100 \times 100 \mu \mathrm{m}^{2}$.

In almost formed planuloids the number of labeled nuclei slightly decreased to $30-50$ per $100 \times 100 \mu \mathrm{m}^{2}$. It was especially noticeable in planuloid chains (Fig. 2C). In this case the most abundant signal was still observed in the evagination, whereas in each subsequent planuloid in the chain it was much weaker. The location of the EdU labeling zone remained the same: the strongest level of label incorporation was detected near the planuloid base. The number of labeled nuclei insignificantly decreased to the distal end, without any signal at the tip.

In swimming planuloids we observed the same pattern of EdU labeling (Fig. 3A, B). The rate of incorporation varied between different specimens from 40 to 60 labeled nuclei per $100 \times 100 \mu \mathrm{m}^{2}$, but the character of label distribution remained constant. The number of labeled nuclei at the posterior end of the planuloid was about 3.2-3.4 times higher than at the anterior end: about $34-41$ and $8-14$ per $100 \times 100 \mu \mathrm{m}^{2}$, respectively. During further development, the planuloids become elongated and start to form tentacle and hypostome anlages at the posterior end, as well as stalk anlagen at the 

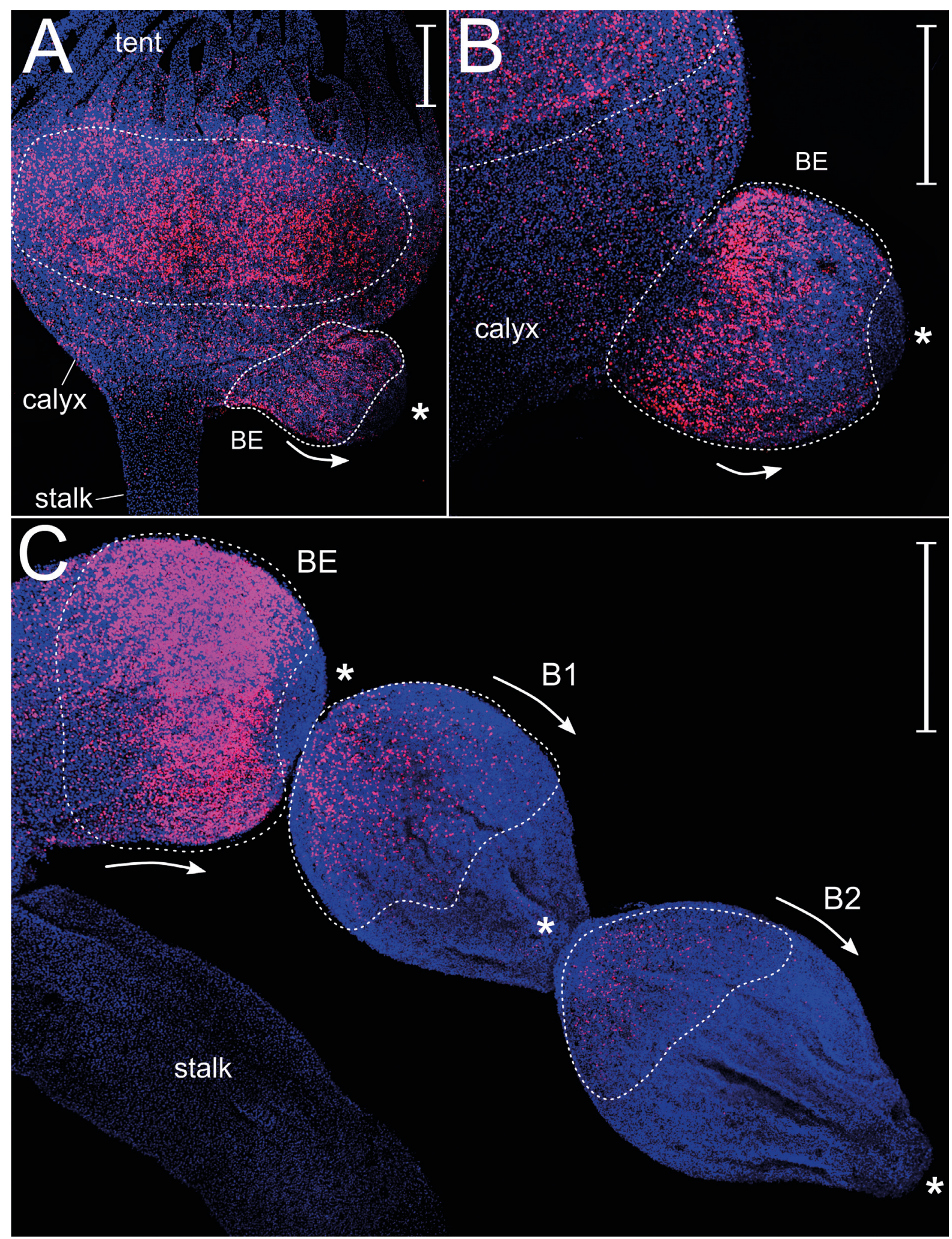

Fig. 2. Polyp and growing buds of C. xamachana, labeled with EdU (pink) and DAPI (blue).

A - polyp with growing bud evagination, B - bud evagination, $C$ - bud evagination and two planuloid buds in chain. Abbreviations: B1, B2 - planuloid buds, BE - bud evagination, tent - tentacles. The functionally anterior end of the planuloid is labeled with an asterisk; arrows show the direction of bud growth; the dotted line marks the border of labeling zone. Scale bar $-100 \mu \mathrm{m}$. 


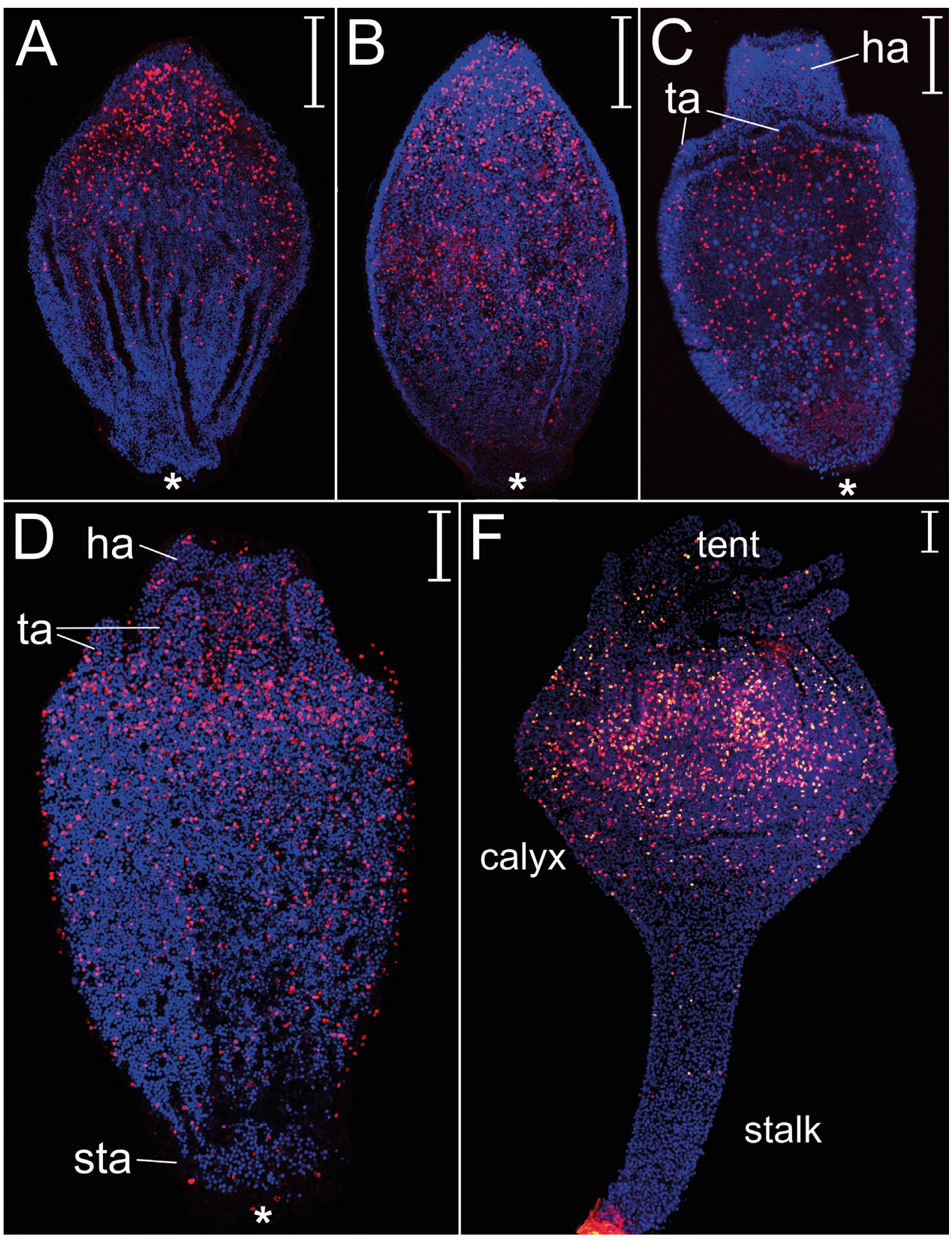

Fig. 3. Planuloid development stages and young polyp of C. xamachana, labeled with EdU (pink and red) and DAPI (blue). A - planuloid, just after separation, B - planuloid, one day after separation, C - late planuloid, D - planuloid before settlement, F - young polyp. Abbreviations: ha - hypostome anlage, sta - stalk anlage, ta - tentacle anlage, tent - tentacles. The functionally anterior end of the planuloid is labeled with an asterisk. Scale bar $-100 \mu \mathrm{m}$. 


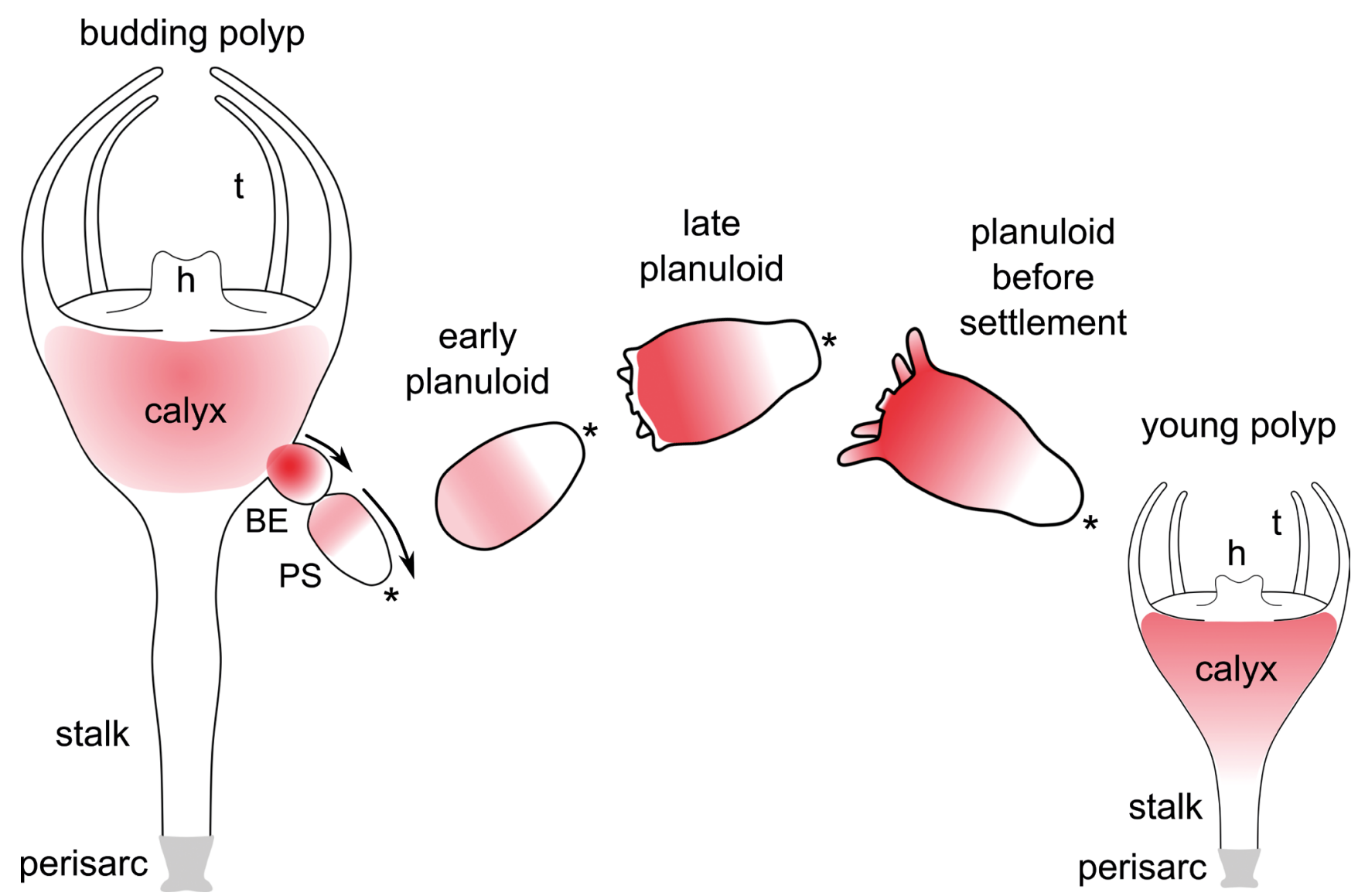

Fig. 4. Scheme of proliferation zone activity at the different stages of planuloid budding in C. xamachana. Abbreviations: BE - bud evagination, $\mathrm{h}$ - hypostome, PS - planuloid before separation, $\mathrm{t}$ - tentacles. The functionally anterior end of the planuloid is labeled with an asterisk; the arrow shows the direction of bud growth. Relative dimensions are not kept.

anterior end (Fig. 3C, D). In this moment the EdU labeling zone occupied the whole body. However, the incorporation rate was the strongest at the area of the tentacle anlages - about 38-42 labeled nuclei per $100 \times 100 \mu \mathrm{m}^{2}$. Fewer labeled nuclei were observed at the tip of the anterior end, where they had not been present before. In total, the number of labeled nuclei at the anterior end of the late planuloid was about $10-14$ per $100 \times 100 \mu \mathrm{m}^{2}$.

After settlement, the planuloid transforms into a young polyp with differentiated calyx, stalk, and tentacles (Fig. 3F). In the young polyp the EdU labeling zone was located at the calyx. The number of labeled nuclei was still high - about $30-40$ per $100 \times 100 \mu \mathrm{m}^{2}-$ and was the largest at the tentacles base - about 42-52 per $100 \times 100 \mu \mathrm{m}^{2}$. Individual labeled cells were also observed in the tentacles and stalk.

\section{Discussion}

In polyps and planuloids of C.xamachana, EdU labeling occurs in several regions during bud growth and planuloid development. This indicates active DNA synthesis, suggesting the presence of functioning proliferation zones during budding and formation of the new polyp.
The general scheme of proliferation activity in C.xamachana polyp is presented in Figure 4.

The earliest stages of budding are usually poorly distinguishable in polyps, since there are no obvious morphological features of future bud anlage. However, it was shown in previous studies that the primary cell source for bud formation is parent polyp tissues. Epidermal and gastrodermal cells can migrate to the budding site and possibly their proliferation provides the bud protrusion forming (Hofmann and Gottlieb, 1991; Hofmann et al., 2003). Subsequently, the active proliferation zone forms in the growing bud. The EdU labeling rate in this region is much higher than in any other part of the polyp body. Besides, the labeling level of calyx tissues does not increase near the budding site. Possibly at this stage the growth of the planuloid is carried out by cell divisions precisely in the bud evagination.

The same process of cell migration to the bud anlage and proliferation activity in the bud protrusion was also observed during lateral budding in Hydra sp. (Otto and Campbell, 1977; Holstein et al., 1991). However, in this case cell proliferation is less important for bud growth than cell movement (Clarkson and Wolpert, 1967). Proliferation activity was also shown during the 
lateral budding of Aurelia aurita, but the labeling level in buds was only slightly higher than in polyp tissues (Balcer and Black, 1991). Although the initial stages of bud anlage formation might be similar in planuloid budding of C.xamachana and lateral budding of other studied species, further steps of bud development differ.

Proliferation activity decreases up to the moment of complete planuloid formation. In the brief period after separation, planuloids do not grow but start to differentiate their own musculature (Khabibulina and Starunov, 2019). Shortly thereafter the new growth phase begins, and proliferation activity increases again. The highest labeling level is observed in the hypostome and tentacle anlages at the posterior end of the planuloid. The forming cells are not necessary immediately involved in tissue composition. They probably accumulate for growth acceleration after settlement.

Interestingly, the anterior end of the planuloid remains unlabeled from the start of bud formation to the late planuloid stage. At this end mostly glandular cells, used for substrate attachment, are located (Van Lieshout and Martin, 1992). Since these cells differentiate early, no proliferation activity occurs in the anterior region until the beginning of stalk formation and settlement. However, even at this stage only a few labeled nuclei are observed.

After settlement the anterior end of the planuloid becomes the oral end of a new polyp. The zone of active DNA synthesis in a young polyp continues to function and expands as the calyx grows, but never involves the tentacles and stalk, where only a few individual labeled nuclei are found. The further growth of tentacles and stalk during the polyp life is apparently provided by cell sources at their bases.

The calyx active proliferation zone is preserved in budding polyps, though the rate of cell divisions in it decreases. Apparently this zone proceeds during the whole life of a C.xamachana polyp. It may act as the cell source not only for budding and body growth, but also for regeneration (Curtis and Cowden, 1974) or jellyfish production by strobilation (Hofmann et al., 2003; Helm, 2018).

Thus, the C.xamachana polyp has one active proliferation zone, which forms at the early budding stage and remains active throughout the polyp's life. Although the activity of this zone changes depending on the growth phase, its relative localization in the body is the same in the growing bud, early and late planuloid, and then in the polyp.

\section{Acknowledgments}

Scientific research was performed at the Chromas Centre and the Centre for Culture Collection of Microorganisms of the Research Park of St. Petersburg State University as well as the Taxon Core Facilities Centre of the Zoological Institute of the Russian Academy of Sciences (St. Petersburg, Russia).

\section{References}

Adler, L. and Jarms, G. 2009. New insights into reproductive traits of scyphozoans: special methods of propagation in Sanderia malayensis Goette, 1886 (Pelagiidae, Semaeostomeae) enable establishing a new classification of asexual reproduction in the class Scyphozoa. Marine Biology 156(7):1411-1420. https://doi.org/10.1007/s00227-0091181-6

Arai, M. N. 2008. The potential importance of podocysts to the formation of scyphozoan blooms: a review; pp. 241246 in Pitt, K. A. and Purcell, J. E. (eds), Jellyfish Blooms: Causes, Consequences, and Recent Advances. Springer, Dordrecht. https://doi.org/10.1007/978-1-4020-97492_16

Balcer, L. J. and Black, R. E. 1991. Budding and strobilation in Aurelia (Scyphozoa, Cnidaria): Functional requirement and spatial patterns of nucleic acid synthesis. Roux's archives of developmental biology 200(1):45-50. https://doi. org/10.1007/BF02457640

Bigelow, R. P. 1892. On a new species of Cassiopea from Jamaica. Zoologischer Anzeiger 15:212-214.

Bigelow, R. P. 1900. The anatomy and development of Cassiopea xamachana. Boston: Boston Society of Natural History. https://doi.org/10.5962/bhl.title.31420

Bocharova, E. S. and Kozevich, I. A. 2011. Modes of reproduction in sea anemones (Cnidaria, Anthozoa). Biology Bulletin 38(9):849-860. https://doi.org/10.1134/ S1062359011090020

Boero, F., Bouillon, J., Piraino, S., and Schmid, V. 2002. Asexual reproduction of the Hydrozoa (Cnidaria); pp. 141-159 in Progress in asexual reproduction. Chichester: John Wiley \& Sons, Ltd.

Chapman, D. M. 1968. Structure, histochemistry and formation of the podocyst and cuticle of Aurelia aurita. Journal of the Marine Biological Association of the United Kingdom 48(1):187-208. https://doi.org/10.1017/ S0025315400032537

Clarkson, S.T. and Wolpert, L. 1967. Bud morphogenesis in Hydra. Nature 214(5090):780-783. https://doi. org/10.1038/214780a0

Curtis, S. K. and Cowden, R. R. 1974. Some aspects of regeneration in the scyphistoma of Cassiopea (Class Scyphozoa) as revealed by the use of antimetabolites and microspectrophotometry. American Zoologist 14(2):851-866. https://doi.org/10.1093/icb/14.2.851

da Silveira, F. L. and Morandini, A. C. 1997. Nausithoe aurea n. sp. (Scyphozoa: Coronatae: Nausithoidae), a species with two pathways of reproduction after strobilation: sexual and asexual. Bijdragen tot de Dierkunde 66(4):235246. https://doi.org/10.1163/26660644-06604004

Fautin, D. G. 2002. Reproduction of cnidaria. Canadian Journal of Zoology 80(10):1735-1754. https://doi.org/10.1139/ z02-133

Fuentes, V., Straehler-Pohl, I., Atienza, D., Franco, I., Tilves, U., Gentile, M., Acevedo, M., Olariaga, A., and Gili, J.-M. 2011. Life cycle of the jellyfish Rhizostoma pulmo (Scyphozoa: Rhizostomeae) and its distribution, seasonality and inter-annual variability along the Catalan coast and the Mar Menor (Spain, NW Mediterranean). Marine Biology 158(10):2247-2266. https://doi.org/10.1007/s00227011-1730-7

Galliot, B. 2012. Hydra, a fruitful model system for 270 years. International Journal of Developmental Biology 56:411423. https://doi.org/10.1387/ijdb.120086bg

Gilchrist, F. G. 1937. Budding and locomotion in the scyphistomas of Aurelia. The Biological Bulletin 72(1):99-124. https://doi.org/10.2307/1537544 
Helm, R. R. 2018. Evolution and development of scyphozoan jellyfish. Biological Reviews 93(2):1228-1250. https://doi. org/10.1111/brv.12393

Hofmann, D. K., Fitt, W. K., and Fleck, J. 2003. Checkpoints in the life-cycle of Cassiopea spp.: control of metagenesis and metamorphosis in a tropical jellyfish. International Journal of Developmental Biology 40(1):331-338.

Hofmann, D. K. and Gottlieb, M. 1991. Bud formation in the scyphozoan Cassiopea andromeda: epithelial dynamics and fate map; pp. 53-59 in Williams, R. B., Cornelius, P. F. S., Hughes, R. G., and Robson, E. A. (eds), Coelenterate Biology: Recent Research on Cnidaria and Ctenophora. Developments in Hydrobiology, vol 66. Springer, Dordrecht. https://doi.org/10.1007/978-94$011-3240-48$

Hofmann, D. K., Neumann, R., and Henne, K. 1978. Strobilation, budding and initiation of scyphistoma morphogenesis in the rhizostome Cassiopea andromeda (Cnidaria: Scyphozoa). Marine Biology 47(2):161-176. https://doi. org/10.1007/BF00395637

Holstein, T.W., Hobmayer, E., and David, C. N. 1991. Pattern of epithelial cell cycling in hydra. Developmental Biology 148(2):602-611. https://doi.org/10.1016/00121606(91)90277-A

Ikeda, H., Ohtsu, K., and Uye, S. I. 2011. Fine structure, histochemistry, and morphogenesis during excystment of the podocysts of the giant jellyfish Nemopilema nomurai (Scyphozoa, Rhizostomeae). The Biological Bulletin 221(3):248-260. https://doi.org/10.1086/ BBLv221n3p248

Khabibulina, V. and Starunov, V. 2019. Musculature development in planuloids of Cassiopeia xamachana (Cnidaria: Scyphozoa). Zoomorphology 138(3):297-306. https://doi. org/10.1007/s00435-019-00444-6

Kikinger, R. 1992. Cotylorhiza tuberculata (Cnidaria: Scyphozoa) - life history of a stationary population. Marine Ecology 13(4):333-362. https://doi. org/10.1111/j.1439-0485.1992.tb00359.x

Lucas, C. H., Graham, W. M., and Widmer, C. 2012. Jellyfish life histories: role of polyps in forming and maintaining scyphomedusa populations. Advances in Marine Biology 63:133-196. https://doi.org/10.1016/B978-0-12-394282$1.00003-X$

Otto, J. J. and Campbell, R. D. 1977. Budding in Hydra attenuata: bud stages and fate map. Journal of Experimental Zoology 200(3):417-428. https://doi.org/10.1002/ jez.1402000311

Pitt, K. A. 2000. Life history and settlement preferences of the edible jellyfish Catostylus mosaicus (Scyphozoa: Rhi- zostomeae). Marine Biology 136(2):269-279. https://doi. org/10.1007/s002270050685

Schiariti, A., Morandini, A. C., Jarms, G., von Glehn Paes, R., Franke, S., and Mianzan, H. 2014. Asexual reproduction strategies and blooming potential in Scyphozoa. Marine Ecology Progress Series 510:241-253. https://doi. org/10.3354/meps10798

Schindelin, J., Arganda-Carreras, I., Frise, E., Kaynig, V., Longair, M., Pietzsch, T., Preibisch, S., Rueden, C., Saalfeld, S., Schmid, B., Tinevez, J.-Y., White, D.J., Hartenstein, V., Eliceiri, K., Tomancak, P., and Cardona, A. 2012. Fiji: an opensource platform for biological-image analysis. Nature Methods 9(7):676-682. https://doi.org/10.1038/nmeth.2019

Shunatova, N. and Borisenko, I. 2020. Proliferating activity in a bryozoan lophophore. PeerJ 8:e9179. https://doi. org/10.7717/peerj.9179

Spangenberg, D. B. 1965. Cultivation of the life stages of Aurelia aurita under controlled conditions. Journal of Experimental Zoology 159(3):303-318. https://doi.org/10.1002/ jez.1401590303

Sugiura, Y. 1963. On the life-history of rhizostome. Medusae I. Anotationes Zoologicae Japonensis 36(4):194-202.

Sugiura, Y. 1966. On the life-history of rhizostome medusae IV. Cephea cephea. Embryologia 9(2):105-122. https://doi. org/10.1111/j.1440-169X.1966.tb00219.x

Thieme, C. and Hofmann, D. K. 2003. Control of head morphogenesis in an invertebrate asexually produced larva-like bud (Cassiopea andromeda; Cnidaria: Scyphozoa). Development Genes and Evolution 213(3):127-133. https://doi. org/10.1007/s00427-003-0300-5

Van Lieshout, J.S. and Martin, V.J. 1992. Development of planuloid buds of Cassiopea xamachana (Cnidaria: Scyphozoa). Transactions of the American Microscopical Society 111(2):89-110. https://doi.org/10.2307/3226666

Werner, B. 1971. Stephanoscyphus planulophorus n. spec., ein neuer Scyphopolyp mit einem neuen Entwicklungsmodus. Helgoländer Wissenschaftliche Meeresuntersuchungen 22(1):120-140. https://doi.org/10.1007/BF01611366

Widmer, C. L. 2006. Life cycle of Phacellophora camtschatica (Cnidaria: Scyphozoa). Invertebrate Biology 125(2):83-90. https://doi.org/10.1111/j.1744-7410.2006.00043.x

Widmer, C. L. 2008. Life Cycle of Chrysaora fuscescens (Cnidaria: Scyphozoa) and a key to sympatric ephyrae. $P a-$ cific Science 62(1):71-82. https://doi.org/10.2984/15346188(2008)62[71:LCOCFC]2.0.CO;2

Wurm, C. A., Neumann, D., Schmidt, R., Egner, A., and Jakobs, S. 2010. Sample preparation for STED microscopy; pp. 185199 in Papkovsky, D. (ed), Live Cell Imaging. Humana Press. https://doi.org/10.1007/978-1-60761-404-3_11 